\title{
Permeabilization of the Nuclear Envelope Following Nanosecond Pulsed Electric Field Exposure
}

Gary L. Thompson ${ }^{1 *}$, Caleb C. Roth ${ }^{2}$, Marjorie A. Kuipers ${ }^{3}$, Gleb P. Tolstykh ${ }^{4}$, Bennett L. Ibey ${ }^{3}$

${ }^{1}$ Oak Ridge Institute for Science \& Education, Joint Base San Antonio Fort Sam Houston, TX, 78234

${ }^{2}$ Department of Radiological Sciences, University of Texas Health Science Center at San Antonio, TX, 78234

${ }^{3}$ Radio Frequency Bioeffects, Bioeffects Division, Human Effectiveness Directorate, 711th Human Performance Wing, Air Force Research Laboratory, Joint Base San Antonio Fort Sam Houston, TX, 78234

${ }^{4}$ General Dynamics IT, Joint Base San Antonio Fort Sam Houston, TX, 78234 


\begin{abstract}
Permeabilization of cell membranes occurs upon exposure to a threshold absorbed dose (AD) of nanosecond pulsed electric fields (nsPEF). The ultimate, physiological bioeffect of this exposure depends on the type of cultured cell and environment, indicating that cell-specific pathways and structures are stimulated. Here we investigate 10 and 600 ns duration PEF effects on Chinese hamster ovary (CHO) cell nuclei, where our hypothesis is that pulse disruption of the nuclear envelope membrane leads to observed cell death and decreased viability $24 \mathrm{~h}$ postexposure. To observe short-term responses to nsPEF exposure, $\mathrm{CHO}$ cells have been stably transfected with two fluorescently-labeled proteins known to be sequestered for cellular chromosomal function within the nucleus histone-2b (H2B) and proliferating cell nuclear antigen (PCNA). H2B remains associated with chromatin after nsPEF exposure, whereas PCNA leaks out of nuclei permeabilized by a threshold AD of 10 and $600 \mathrm{~ns}$ PEF. A downturn in $24 \mathrm{~h}$ viability, measured by MTT assay, is observed at the number of pulses required to induce permeabilization of the nucleus.
\end{abstract}

Keywords: nsPEF, chromatin, PCNA, H2B, electroporation

*Correspondence to: gary.l.thompson.3@gmail.com

\title{
1. Introduction
}

Nanosecond pulsed electric field (nsPEF) exposure initiates a host of biochemical pathways, which can be ubiquitous $[1,2]$ or specific to the cell-type $[3,4]$, and leads to long-term, physiological effects. Exposure parameters such as dosage [5] and environmental conditions determine cell fate. Pulsed electric fields at durations shorter than the charging time of the outer plasma membrane (typically $<100 \mathrm{~ns}$ for an average cell diameter of $10 \mu \mathrm{m}$ ) have been postulated to directly interact with intracellular components [6]. The effects of 10 or $60 \mathrm{~ns}$ PEF on organelles such as nuclei [7] have been published. Even sub-nuclear speckle structures and their functions in support of DNA replication are impacted [8], although no difference in changes of nuclear size and survivability between $60 \mathrm{~ns}$ and $300 \mathrm{~ns}$ PEF was found for unsynchronized HCT116 cells [7]. Herein, the hypothesis that the extent and temporal relationship of disruption of the nuclear membrane and its contents is a predictor of ultimate cell survivability following exposure to $10 \mathrm{~ns}$ and $600 \mathrm{~ns} \mathrm{PEF}$ is reanalyzed with fluorescently-labeled proteins important for management of DNA.

The integrity of the nuclear membrane determines cell fate via control of genetic material. During mitosis, nuclear envelope breakdown (NEB) allows distribution of nucleic acids between the daughter cells. Breakdown is administered by cytoskeletal tensioning and rupture of the nuclear membrane [9], which allows chromosomes to separate along mitotic spindles. Independent of the cell cycle, external stressors can influence function of the nuclear membrane by means of mechanotransduction [10]. Changes in gene expression can be directed via alteration of the shape of nuclei [11], and epigenetic modifications causing shifts in intranuclear structures and organization can be detected as changes in the mechanical properties of the nucleus [12]. Cytoskeleton-mediated mechanotransduction impacts chromatin condensation, nuclear membrane stability, and ultimately, cell proliferation [13].

Permeabilization of the nuclear membrane can be indirectly followed using fluorescent protein-tagged histone$2 \mathrm{~b}(\mathrm{H} 2 \mathrm{~B})$ and proliferating cell nuclear antigen (PCNA). A precedent for using this pair of proteins as indicators of cell cycle progression has been set in the literature [14]. H2B is one of four types of histone proteins around which DNA tightly winds to form nucleosomes, which compact in an $\mathrm{Mg}^{2+}-[15]$ and ionic strength- [16] dependent manner into chromatin. H2B has limited mobility when associated with nucleosomes, as demonstrated by fluorescence recovery after photobleaching (FRAP) [17], and colocalizes more often than other histones with actively transcribed chromatin [18]. (However, H2B does not colocalize with nuclear speckles [19].) Posttranslational modification of H2B with the ubiquitin protein directly causes decompaction of chromatin [16], exposing sections of chromatin for access by replication proteins [20]. Monoubiquitination of H2B (H2Bub1) can occur in response to DNA damage [20], such as double strand breaks incurred by direct exposure to ionizing radiation [21,22]. Ostensibly, the H2Bub1-mediated response allows access by the repair machinery. Yet, the H2Bub1-mediated response takes at least $15 \mathrm{~s}$ to occur [23], which is too slow to cause the decompaction observed with all cellular disruptions.

PCNA is a protein that forms a sliding clamp on DNA to tether polymerases and is transiently attached during replication [24]. Fluorescent protein-tagged PCNA is a marker of S-phase timepoints based on association with replication loci and their distribution, and it has been used to show that replication loci are distinct from speckles or 
coiled bodies [25]. Unlike H2B, PCNA often separates from DNA throughout the cell cycle [18] and is found rapidly diffusing within the cytoplasm when the nuclear envelope breaks down [26]. Like H2B, monoubiquitination of PCNA occurs in response to DNA damage [27] in a $\mathrm{Mg}^{2+}$-dependent manner [28]. Monoubiquitinated PCNA is tightly bound to damaged chromatin [29] and via RAD6 and RAD18 directs DNA polymerase $\eta$-mediated translesion DNA synthesis for repair in human cells [30]. Notably, monoubiquitination of H2B and PCNA in human cell lines can result from the same pathway, via CDK9 phosphorylation of UBE2A [31].

Exposure of cells to higher doses of nsPEF apparently disrupts intracellular components [32]. Longer-duration pulses are expected to more thoroughly permeabilize plasma membranes. Either this permeabilization initiates cascade(s) leading to disruption of intracellular components, or nsPEFs directly interact with intracellular components, or a combination of both. Our results indicate that there is no direct effect from either 10 or $600 \mathrm{~ns}$ PEF on chromatin, although an indirect effect occurs from perturbation of the nuclear membrane, which impacts cell death and survival.

\section{Materials and methods}

\subsection{Cells and Reagents}

Chinese hamster ovary (CHO) cells have a dearth of voltage-gated ion channels, making them a good cell culture model for in vitro bioelectric experimentation [33]. CHO-K1 cells and media components were acquired from American Type Culture Collection (ATCC, Manassas, VA), and cells were grown according to protocol from ATCC. For transfection of green fluorescent protein-histone 2B (GFP-H2B), red fluorescent protein-proliferating cell nuclear antigen (RFP-PCNA), and mEmerald-tubulin into CHO-K1 cells, an Effectene kit (Qiagen, Gaithersburg, MD) was used, and the lines were maintained using G418 (Calbiochem, Philadelphia, PA). Stable transfection of a line of CHO-K1 with both GFP-H2B and RFP-PCNA was successful. Functionally, chromatin patterns were distinguishable within GFP-H2B images, and RFP-PCNA diffused into the cytoplasm after NEB during mitosis (data not shown). A custom buffer solution used throughout the experiments consisted of $2 \mathrm{mM}$ $\mathrm{MgCl} 2,5 \mathrm{mM}$ KCL, $10 \mathrm{mM}$ 4-(2-hydroxyethyl)-1-piperazineethanesulfonic acid (HEPES), $10 \mathrm{mM}$ Glucose, 2 $\mathrm{mMCaCl}$, and $135 \mathrm{mM} \mathrm{NaCl}$ (Sigma-Aldrich, St. Louis, MO). The buffer osmolarity was measured, and $\mathrm{pH}$ was adjusted to 7.4 using $\mathrm{NaOH}$. In experiments where calcium was removed from the outside solution, $2 \mathrm{mM} \mathrm{CaCl} 2$ was replaced by $2 \mathrm{mM}$ potassium ethylene glycol tetraacetic acid (K-EGTA) (Sigma-Aldrich) added to the buffer solution. Imaging was performed at room temperature, between $22{ }^{\circ} \mathrm{C}$ and $24{ }^{\circ} \mathrm{C}$.

\subsection{Pulsing System}

A Zeiss 710 LSM confocal microscope (Carl Zeiss MicroImaging GmbH, Jena, Germany) with a DIC40X 1.2NA objective (Carl Zeiss MicroImaging GmbH, Germany) was used to image the CHO-K1 cells. For $600 \mathrm{~ns} \mathrm{PEF}$ exposures, a stimulating electrode composed of parallel tungsten wires $(85.2-\mu \mathrm{m}$ separation) was crafted in-house and mounted at a 30-35 deg angle on an electrically controllable micromanipulator (Sutter Instruments MP252). The pulsing system (made at Old Dominion University (ODU)) has been described in previous publications [3,34]. For this study, pulse durations of $10 \mathrm{~ns}$ and $600 \mathrm{~ns}$ were chosen because of different charging time effects on the plasma membrane [6,35]. For $10 \mathrm{~ns}$ PEF exposures, experiments were performed at ODU with a similar microscopebased pulsing system. EF strengths of $18.2 \mathrm{kV} / \mathrm{cm}$ and $27.7 \mathrm{kV} / \mathrm{cm}$ for $600 \mathrm{~ns}$ duration pulses and $150 \mathrm{kV} / \mathrm{cm}$ for 10 ns duration pulses were used as indicated with the respective pulsing systems. A finite-difference time-domain model previously was constructed based on the electrode geometry, in previous publications, to calculate the electric field amplitude at the cell position [36]. Due to inherent electric field nonuniformity near the electrodes, the cells were positioned at $50 \mu \mathrm{m}$ below the electrodes using the micromanipulator.

For cell survival experiments, cuvette-based exposure in a custom Marx bank pulser (made at ODU) capable of delivering 600-ns duration pulses was used. A high voltage power supply (Glassman Series EH) charges the Marx bank until breakdown of an air spark-gap with controllable separation. Cuvette gap distance, spark-gap separation and power supply voltage determine the pulse amplitude and rate. Amplitude of $16.7 \mathrm{kV} / \mathrm{cm}$ at approximately $1 \mathrm{~Hz}$ was used in this study. Viability of cells at $24 \mathrm{~h}$ after nsPEF exposure was determined using colorimetric 3-[4,5-dimethylthiazol-2-yl]-2,5-diphenyltetrazolium bromide (MTT, from ATCC).

\subsection{Immunofluorescence Microscopy}

For imaging of nuclear lamin, CHO-K1 cells were grown for $24 \mathrm{~h}$ in a petri dish with $500 \mu \mathrm{m}$ grids (Ibidi $\mu$ dish). Within 15 minutes of exposure to $600 \mathrm{~ns}$ PEF of $27.7 \mathrm{kV} / \mathrm{cm}$ and $0,1,5,10$ or 20 pulses in calciumcontaining buffer, cells were fixed with $4 \%$ paraformaldehyde in DPBS. Fixed cells were labeled with a monoclonal 
antibody for lamin A/C (Active Motif \#39288) and stained with a secondary anti-mouse IgG antibody conjugated with Chromeo 505 (Active Motif \#15030). Exposed cells were relocated using the grid for confocal imaging.

\section{Results and discussion}

\section{$3.1 \mathrm{H} 2 \mathrm{~B}$ and Chromosomal Stability given 600 ns PEF}

With 20 pulses of 600 ns PEF exposure, FRAP with H2B (Fig. 1A) revealed sustained attachment of histone $\mathrm{H} 2 \mathrm{~B}$ to chromosomal structures and retention of DNA within the nucleus following pulse exposure, as fluorescence intensity does not recover within the photobleached area. Retention of GFP-H2B within the nucleus confirmed that it is an appropriate indicator of nuclear volume. However, the punctate GFP-H2B fluorescence became diffuse afterward, indicating that chromosomes have become unpacked and less organized.

To check if ubiquitylation of damaged DNA results in the observation of diffuse GFP-H2B following nsPEF exposure, external calcium and magnesium were not added in the buffer solution (Fig. 1B). Calcium and magnesium are required for the $\mathrm{E} 3$ ubiquitin ligase activity responsible for ubiquitination of H2B. Prior to nsPEF exposure, chromatin remained compact as indicated by punctate GFP-H2B even without external divalent cations. Following exposure, chromatin decompaction occurred rapidly, even in the absence of external calcium and magnesium, suggesting that the mechanism underlying nsPEF-induced chromatin disruption is not initiated by ubiquitylation.

\subsection{Nuclear Membrane Rupture following nsPEF Exposure}

Decrease of PCNA localized within the bounds of the nuclear membrane would signify compromise of nuclear membrane integrity, and here we assume that total integrated fluorescence intensity of RFP-PCNA within the nucleus over time is an appropriate, relative indicator of PCNA leakage from the nucleus. Given 20 pulses in calcium-containing buffer, a decrease in fluorescence intensity of RFP-PCNA within nuclei occurred as cells swelled and blebbed (Fig. 2).

RFP-PCNA fluorescence in the cytosol increased drastically within $750 \mathrm{~s}$ of exposure to 20 pulses. The 24h MTT assay revealed a significant decrease in viability of non-transfected CHO-K1 cells given 10 and 20 pulses in calcium-containing buffer and 20 pulses in calcium-free buffer (Fig. 3A). This trend reflects the increasing localization of cortical lamin within the nucleus with increasing number of pulses (Fig. 3B).

In the presence of external calcium, PEF with duration of $10 \mathrm{~ns}$ induced PCNA leakage that is greater and occurs earlier given more pulses (> 50) of $10 \mathrm{~ns}$ PEF (Fig. 4A). The trend in PCNA leakage is apparent upon visual observation (Fig. 4C). Quantitative comparison of results from nsPEF exposures with multiple different physical pulse parameters required absorbed doses to be calculated [5]. The absorbed dose (AD) is proportional to the squared electric field strength $\left(E^{2}\right)$, pulse duration $(\tau)$, and number of pulses $(n): A D=E^{2} * \tau * n$. Given the parameters used with the microscope systems in this study, the AD of a cell exposed to 20, $600 \mathrm{~ns}$ PEF of 27.7 $\mathrm{kV} / \mathrm{cm}$ is $127 \mathrm{~J} / \mathrm{g}$. For 100 pulses of $10 \mathrm{~ns} P E F$, the AD is $311 \mathrm{~J} / \mathrm{g}$. Thus, the highest AD given a $600 \mathrm{~ns} P E F$ is about $41 \%$ of the AD from enough $10 \mathrm{~ns}$ PEFs to consistently observe PCNA leakage from the nucleus.

Comparing trends in $24 \mathrm{~h}$ viability results, the $\mathrm{AD}$ corresponding to $50 \%$ lethal dose $\left(\mathrm{LD}_{50}\right)$ is more than an order of magnitude greater for $10 \mathrm{~ns}$ PEF in calcium buffer than for $600 \mathrm{~ns}$ PEF in calcium buffer (Fig. 4B). Although the AD's for 10 and 600 ns PEF at which PCNA leakage is observed are on the same order of magnitude, the $24 \mathrm{~h}$ viability corresponding to those AD's is drastically greater for $10 \mathrm{~ns}$ PEF. Speculatively, permeabilization of cells following multiple, $600 \mathrm{~ns}$ PEF initiates physiological responses different from $10 \mathrm{~ns}$ PEF exposure. Yet, the number of pulses of both $600 \mathrm{~ns}$ and $10 \mathrm{~ns}$ PEF that elicit PCNA leakage also cause a noticeable downturn in $24 \mathrm{~h}$ viability.

\section{Summary}

Nuclear permeabilization occurs at higher number of pulses and AD, both for 10 and $600 \mathrm{~ns}$ PEF, and correlates with disruption of the lamin cortex following $600 \mathrm{~ns}$ PEF exposure. Nuclear permeabilization also correlates with a decrease in viability at $24 \mathrm{~h}$, for both 10 and $600 \mathrm{~ns}$ PEF. The fact that $10 \mathrm{~ns}$ and $600 \mathrm{~ns}$ viabilities differ vastly for a given $\mathrm{AD}$, while similar AD's for each pulse duration elicits membrane permeabilization, indicates that cell-specific pathways are initiated selectively by pulse duration. Apparently, permeabilization of the cell resulting from multiple, longer-duration pulses causes irrecoverable physiological damage, whereas permeabilization from $10 \mathrm{~ns}$ pulses (below a threshold $\mathrm{AD}$ ) does not.

NEB naturally occurs during the cell cycle, and if the relevant repair system remains functional, cells can recover from nsPEF-induced nuclear membrane permeabilization. Repair of the nuclear envelope after mitosis 
requires spatiotemporal orchestration of a host of molecules that prepare chromatin and recruit membrane from the endoplasmic reticulum (ER) [37]. These molecules include microtubules, which have been observed to depolymerize following multiple $600 \mathrm{~ns}$ PEF [32]. With regard to the speed of possible recovery, plasma membrane permeabilization has been observed to last several minutes, depending upon $\mathrm{AD}$ and cell type [38]. It is likely that recovery of nuclear membrane integrity also takes minutes. For example, once the ER membrane has been recruited to the chromatin at the end of mitosis, a functioning nucleus is formed within $\sim 12 \mathrm{~min}$ in human osteosarcoma cells [39]. Furthermore, exposure to $10 \mathrm{~ns}$ PEF of a similar AD used here resulted in decreased elasticity of CHO-K1 cells that lasted for scores of minutes [40]. Disruption of the lamina [41] and the nucleus could contribute substantially to such a decrease in cellular elasticity.

Pakhomova et al. have shown that the rate of increase of internal osmotic pressure and calcium influx can explain the rates of intracellular membrane permeabilization and cell death [42,43]. Here, longer microscopy acquisition times and more cells are needed to accurately calculate the rate of changes of the nucleus for a given AD. To determine the mechanism(s) behind nsPEF-induced disruption of nuclei, future investigations can attempt to control osmotic conditions of the cytosol.

\section{Conflict of Interest}

The authors declare no conflict of interest.

\section{Acknowledgements}

The authors would like to thank Dr. Xiao Shu for constructing the custom high voltage pulsing systems and Dr. Andrei Pakhomov for access to the 10 ns PEF microscopy system, both from Old Dominion University. We wish to thank the Oak Ridge Institute for Science \& Education Postdoctoral Research Associateship program and the Air Force Research Laboratory for providing us with the opportunity to conduct this study. This study was supported by a grant from the Air Force Office of Scientific Research (AFOSR 13RH08COR). 


\section{References}

[1] A.G. Pakhomov, A.M. Bowman, B.L. Ibey, F.M. Andre, O.N. Pakhomova, K.H. Schoenbach, Lipid nanopores can form a stable, ion channel-like conduction pathway in cell membrane, Biochem. Biophys. Res. Commun., 385 (2009) 181-6.

[2] G.P. Tolstykh, H.T. Beier, C.C. Roth, G.L. Thompson, B.L. Ibey, 600ns pulse electric field-induced phosphatidylinositol 4, 5-bisphosphate depletion, Bioelectrochemistry, 100 (2014) 80-87.

[3] B.L. Ibey, C.C. Roth, A.G. Pakhomov, J.A. Bernhard, G.J. Wilmink, O.N. Pakhomova, Dose-dependent thresholds of 10-ns electric pulse induced plasma membrane disruption and cytotoxicity in multiple cell lines, PLoS ONE, 6 (2011) e15642.

[4] L.E. Estlack, C.C. Roth, G.L. Thompson III, W.A. Lambert III, B.L. Ibey, Nanosecond pulsed electric fields modulate the expression of Fas/CD95 death receptor pathway regulators in U937 and Jurkat Cells, Apoptosis, 19 (2014) 1755-1768.

[5] A.G. Pakhomov, A. Phinney, J. Ashmore, K. Walker III, J.F. Kolb, S. Kono, K.H. Schoenbach, M.R. Murphy, Characterization of the cytotoxic effect of high-intensity, 10-ns duration electrical pulses, Plasma Science, IEEE Transactions on, 32 (2004) 1579-1586.

[6] K.H. Schoenbach, R.P. Joshi, J.F. Kolb, N. Chen, M. Stacey, P.F. Blackmore, E.S. Buescher, S.J. Beebe, Ultrashort electrical pulses open a new gateway into biological cells, Proceedings of the IEEE, 92 (2004) $1122-1137$.

[7] E.H. Hall, K.H. Schoenbach, S.J. Beebe, Nanosecond pulsed electric fields induce apoptosis in p53-wildtype and p53-null HCT116 colon carcinoma cells, Apoptosis, 12 (2007) 1721-31.

[8] N. Chen, A.L. Garner, G. Chen, Y. Jing, Y. Deng, R.J. Swanson, J.F. Kolb, S.J. Beebe, R.P. Joshi, K.H. Schoenbach, Nanosecond electric pulses penetrate the nucleus and enhance speckle formation, Biochem. Biophys. Res. Commun., 364 (2007) 220-5.

[9] J. Beaudouin, D. Gerlich, N. Daigle, R. Eils, J. Ellenberg, Nuclear envelope breakdown proceeds by microtubule-induced tearing of the lamina, Cell, 108 (2002) 83-96.

[10] T. Iskratsch, H. Wolfenson, M.P. Sheetz, Appreciating force and shape [mdash] the rise of mechanotransduction in cell biology, Nature Reviews Molecular Cell Biology, (2014).

[11] C.H. Thomas, J.H. Collier, C.S. Sfeir, K.E. Healy, Engineering gene expression and protein synthesis by modulation of nuclear shape, Proc. Natl. Acad. Sci. U.S.A., 99 (2002) 1972-7.

[12] J.D. Pajerowski, K.N. Dahl, F.L. Zhong, P.J. Sammak, D.E. Discher, Physical plasticity of the nucleus in stem cell differentiation, Proc. Natl. Acad. Sci. U.S.A., 104 (2007) 15619-24.

[13] M. Versaevel, T. Grevesse, S. Gabriele, Spatial coordination between cell and nuclear shape within micropatterned endothelial cells, Nature Communications, 3 (2012) 671.

[14] M.A. Kuipers, T.J. Stasevich, T. Sasaki, K.A. Wilson, K.L. Hazelwood, J.G. McNally, M.W. Davidson, D.M. Gilbert, Highly stable loading of $\mathrm{Mcm}$ proteins onto chromatin in living cells requires replication to unload, The Journal of Cell Biology, 192 (2011) 29-41.

[15] L.J. Jason, S.C. Moore, J. Ausio, G. Lindsey, Magnesium-dependent association and folding of oligonucleosomes reconstituted with ubiquitinated H2A, J. Biol. Chem., 276 (2001) 14597-601.

[16] B. Fierz, C. Chatterjee, R.K. McGinty, M. Bar-Dagan, D.P. Raleigh, T.W. Muir, Histone H2B ubiquitylation disrupts local and higher-order chromatin compaction, Nat. Chem. Biol., 7 (2011) 113-9.

[17] H. Kimura, P.R. Cook, Kinetics of core histones in living human cells: little exchange of H3 and H4 and some rapid exchange of H2B, J. Cell Biol., 153 (2001) 1341-53.

[18] J. Essers, A.F. Theil, C. Baldeyron, W.A. van Cappellen, A.B. Houtsmuller, R. Kanaar, W. Vermeulen, Nuclear dynamics of PCNA in DNA replication and repair, Mol. Cell. Biol., 25 (2005) 9350-9.

[19] I.E. Schor, D. Llères, G.J. Risso, A. Pawellek, J. Ule, A.I. Lamond, A.R. Kornblihtt, Perturbation of chromatin structure globally affects localization and recruitment of splicing factors, PLoS ONE, 7 (2012) e48084.

[20] K. Nakamura, A. Kato, J. Kobayashi, H. Yanagihara, S. Sakamoto, D.V.N.P. Oliveira, M. Shimada, H. Tauchi, H. Suzuki, S. Tashiro, L. Zou, K. Komatsu, Regulation of homologous recombination by RNF20dependent H2B ubiquitination, Mol. Cell, 41 (2011) 515-28.

[21] A.A. Friedl, B. Mazurek, D.M. Seiler, Radiation-induced alterations in histone modification patterns and their potential impact on short-term radiation effects, Front Oncol, 2 (2012) 117.

[22] M.J. Kruhlak, A. Celeste, G. Dellaire, O. Fernandez-Capetillo, W.G. Müller, J.G. McNally, D.P. BazettJones, A. Nussenzweig, Changes in chromatin structure and mobility in living cells at sites of DNA doublestrand breaks, The Journal of Cell Biology, 172 (2006) 823-834. 
[23] C. Liu, J. Wu, S.C. Paudyal, Z. You, X. Yu, CHFR is important for the first wave of ubiquitination at DNA damage sites, Nucleic Acids Res., 41 (2013) 1698-710.

[24] C. Wyman, M. Botchan, DNA Replication: A familiar ring to DNA polymerase processivity, Current Biology, 5 (1995) 334-337.

[25] H. Leonhardt, H.-P. Rahn, P. Weinzierl, A. Sporbert, T. Cremer, D. Zink, M.C. Cardoso, Dynamics of DNA replication factories in living cells, The Journal of Cell Biology, 149 (2000) 271-280.

[26] A. Sporbert, P. Domaing, H. Leonhardt, M.C. Cardoso, PCNA acts as a stationary loading platform for transiently interacting Okazaki fragment maturation proteins, Nucleic Acids Res., 33 (2005) 3521-8.

[27] C. Hoege, B. Pfander, G.-L. Moldovan, G. Pyrowolakis, S. Jentsch, RAD6-dependent DNA repair is linked to modification of PCNA by ubiquitin and SUMO, Nature, 419 (2002) 135-41.

[28] K. Tanaka, L. Waxman, A.L. Goldberg, ATP serves two distinct roles in protein degradation in reticulocytes, one requiring and one independent of ubiquitin, J. Cell Biol., 96 (1983) 1580-5.

[29] K. Watanabe, S. Tateishi, M. Kawasuji, T. Tsurimoto, H. Inoue, M. Yamaizumi, Rad18 guides poleta to replication stalling sites through physical interaction and PCNA monoubiquitination, EMBO J., 23 (2004) 3886-96.

[30] P.L. Kannouche, J. Wing, A.R. Lehmann, Interaction of human DNA polymerase \$leta \$ with monoubiquitinated PCNA: a possible mechanism for the polymerase switch in response to DNA damage, Molecular Cell, 14 (2004) 491-500.

[31] A. Shchebet, O. Karpiuk, E. Kremmer, D. Eick, S.A. Johnsen, Phosphorylation by cyclin-dependent kinase-9 controls ubiquitin-conjugating enzyme-2A function, Cell Cycle, 11 (2012) 2122-2127.

[32] G.L. Thompson, C.C. Roth, D.R. Dalzell, M. Kuipers, B.L. Ibey, Calcium influx affects intracellular transport and membrane repair following nanosecond pulsed electric field exposure, J Biomed Opt, 19 (2014) 055005.

[33] N. Gamper, J.D. Stockand, M.S. Shapiro, The use of Chinese hamster ovary (CHO) cells in the study of ion channels, J Pharmacol Toxicol Methods, 51 (2005) 177-85.

[34] R.L. Vincelette, C.C. Roth, M.P. McConnell, J.A. Payne, H.T. Beier, B.L. Ibey, Thresholds for phosphatidylserine externalization in chinese hamster ovarian cells following exposure to nanosecond pulsed electrical fields (nsPEF), (2013).

[35] G. Saulis, R. Saule, A. Bitinaite, N. Zurauskiene, V. Stankevic, S. Balevicius, Theoretical Analysis and Experimental Determination of the Relationships Between the Parameters of the Electric Field Pulse Required to Electroporate the Cells, Plasma Science, IEEE Transactions on, 41 (2013) 2913-2919.

[36] B.L. Ibey, D.G. Mixon, J.A. Payne, A. Bowman, K. Sickendick, G.J. Wilmink, W.P. Roach, A.G. Pakhomov, Plasma membrane permeabilization by trains of ultrashort electric pulses, Bioelectrochemistry, 79 (2010) $114-21$.

[37] S. Güttinger, E. Laurell, U. Kutay, Orchestrating nuclear envelope disassembly and reassembly during mitosis, Nature Reviews Molecular Cell Biology, 10 (2009) 178-191.

[38] A.G. Pakhomov, J.F. Kolb, J.A. White, R.P. Joshi, S. Xiao, K.H. Schoenbach, Long-lasting plasma membrane permeabilization in mammalian cells by nanosecond pulsed electric field (nsPEF), Bioelectromagnetics, 28 (2007) 655-63.

[39] D.J. Anderson, M.W. Hetzer, Reshaping of the endoplasmic reticulum limits the rate for nuclear envelope formation, The Journal of Cell Biology, 182 (2008) 911-924.

[40] G.L. Thompson, C. Roth, G. Tolstykh, M. Kuipers, B.L. Ibey, Disruption of the actin cortex contributes to susceptibility of mammalian cells to nanosecond pulsed electric fields, Bioelectromagnetics, 35 (2014) 262 72.

[41] J. Lammerding, P.C. Schulze, T. Takahashi, S. Kozlov, T. Sullivan, R.D. Kamm, C.L. Stewart, R.T. Lee, Lamin A/C deficiency causes defective nuclear mechanics and mechanotransduction, Journal of Clinical Investigation, 113 (2004) 370.

[42] O.N. Pakhomova, B.W. Gregory, I. Semenov, A.G. Pakhomov, Two modes of cell death caused by exposure to nanosecond pulsed electric field, PLoS ONE, 8 (2013) e70278.

[43] O.N. Pakhomova, B. Gregory, I. Semenov, A.G. Pakhomov, Calcium-mediated pore expansion and cell death following nanoelectroporation, Biochim. Biophys. Acta, 1838 (2014) 2547-54. 
Figure 1. (A) FRAP during exposure of CHO cells expressing GFP-H2B to 20 pulses of $600 \mathrm{~ns}$ at $18.2 \mathrm{kV} / \mathrm{cm}$ in buffer containing $2 \mathrm{mM}$ calcium shows that at $30 \mathrm{~s}$ afterwards, the cells have swollen (top), and then as the nuclei shrink or become displaced, chromatin becomes disorganized, but GFP-H2B (bottom) remains attached to the DNA and neither exits the nuclear envelope nor diffuses into the photobleached region. (B) Standard deviation Z-stack projections of the GFP-H2B channel shows that denial of external calcium and magnesium delays but does not preclude change in morphology of the nucleus and perturbation of chromatin structure following 20 pulses of $600 \mathrm{~ns}$ at $18.2 \mathrm{kV} / \mathrm{cm}$. A standard deviation Z-stack projection (bottom right) of the sum Z-stack projections of the $0 \mathrm{~s}$ and 40 s stacks emphasizes changes that occur between these times.

Figure 2. Representative CHO cells stably expressing RFP-PCNA exhibit nuclear membrane permeabilization by PCNA leakage (bottom) after exposure to 20 pulses of $600 \mathrm{~ns}$ duration at $27.7 \mathrm{kV} / \mathrm{cm}$. Buffer included external calcium. PCNA leakage appears to correlate with abrupt swelling and then shrinking of the nucleus from elongated to oval in the DIC (top) and GFP-H2B (middle) channels, respectively. DIC images have been processed by subtracting the image after filtering with a Gaussian blur of $5 \mu \mathrm{m}$ radius, and brightness and contrast have been enhanced for Z-stack sums of fluorescence images.

Figure 3. (A) MTT assays were used to determine percent viability (left axis) at $24 \mathrm{~h}$ after exposure to 0 (sham), 1 , 5,10 or 20 pulses (p) of $600 \mathrm{~ns}$ duration at $16.7 \mathrm{kV} / \mathrm{cm}$ in 1-mm gap cuvettes for CHO cells. Error bars represent SEM for three independent trials run in triplicate. Nuclear permeabilization is represented by maximum percent increase in RFP-PCNA fluorescence in the cytosol (right axis) within $750 \mathrm{~s}$ of nsPEF exposure. Error bars represent SEM for at least 16 randomly chosen cells. (B) Immunofluorescence staining of $\mathrm{CHO}$ cells for lamin $\mathrm{A} / \mathrm{B}$ with Chromeo 505 shows increasing localization of lamin within the nucleus after exposure to an increasing number of pulses $(0,1,5,10$ and 20) of $600 \mathrm{~ns}$ duration at $27.7 \mathrm{kV} / \mathrm{cm}$ in calcium-containing buffer. Cells were fixed using $4 \%$ paraformaldehyde within 15 min of exposure.

Figure 4. (A) $\mathrm{CHO}$ cells were used to determine nuclear membrane permeabilization per RFP-PCNA leakage after exposure to 20,50 or 100 pulses (p) of $10 \mathrm{~ns}$ duration at $150 \mathrm{kV} / \mathrm{cm}$. Curves represent an average from 36 cells for 20 p, 26 for 50 p, and 42 for 100 p. Error bars represent SEM. (B) Viability results from MTT assays replotted against absorbed dose. Data for $10 \mathrm{~ns}$ exposures are approximated from Ibey et al. [2011]. (C) CHO cells stably expressing RFP-PCNA exhibit nuclear membrane permeabilization indicated by PCNA leakage after exposure 100 pulses of $10 \mathrm{~ns}$ duration at $150 \mathrm{kV} / \mathrm{cm}$. Buffer included external calcium. 
$\stackrel{\text { Figure }}{\mathrm{A}}$

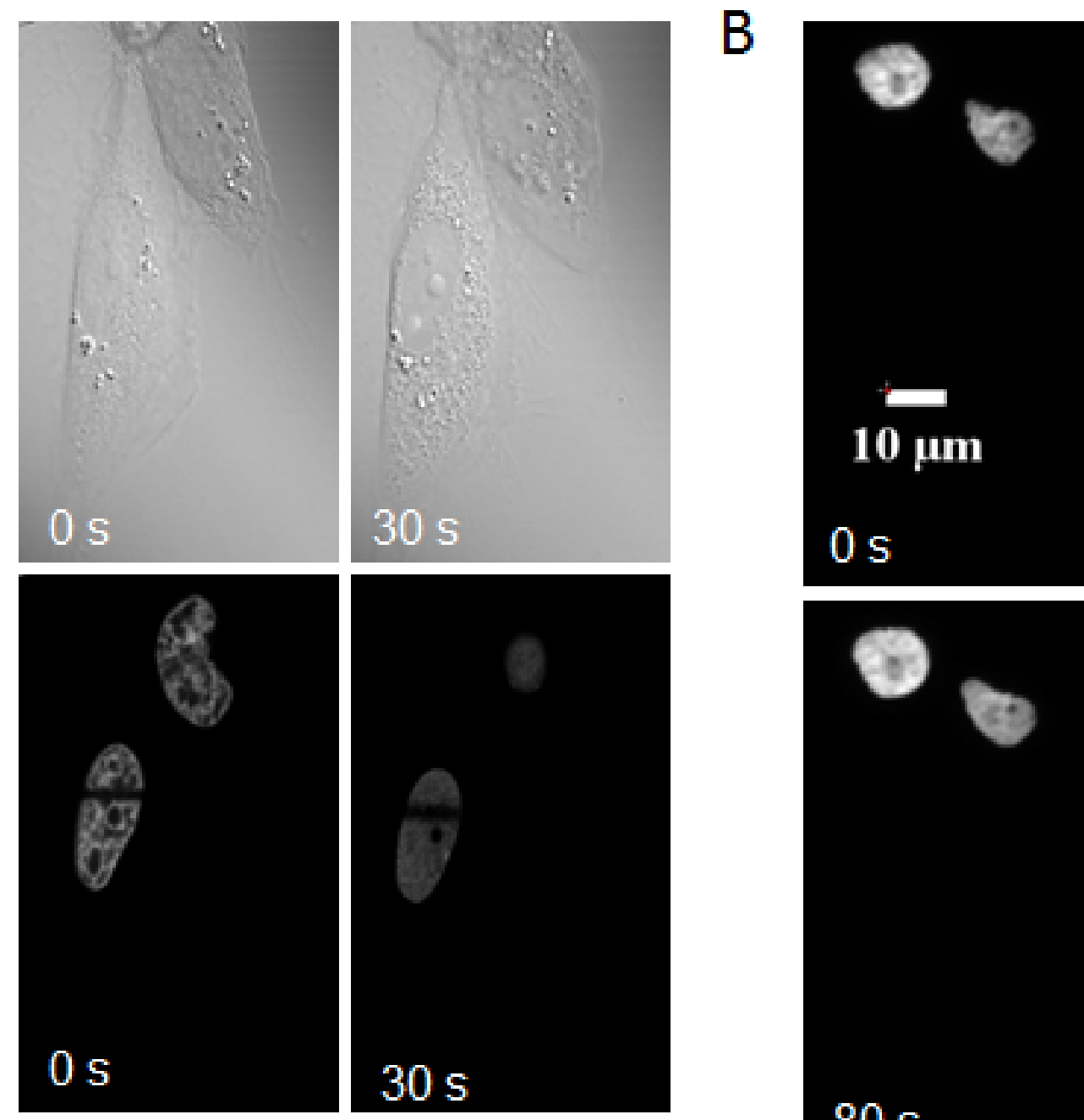

B

$0 \mathrm{~s}$

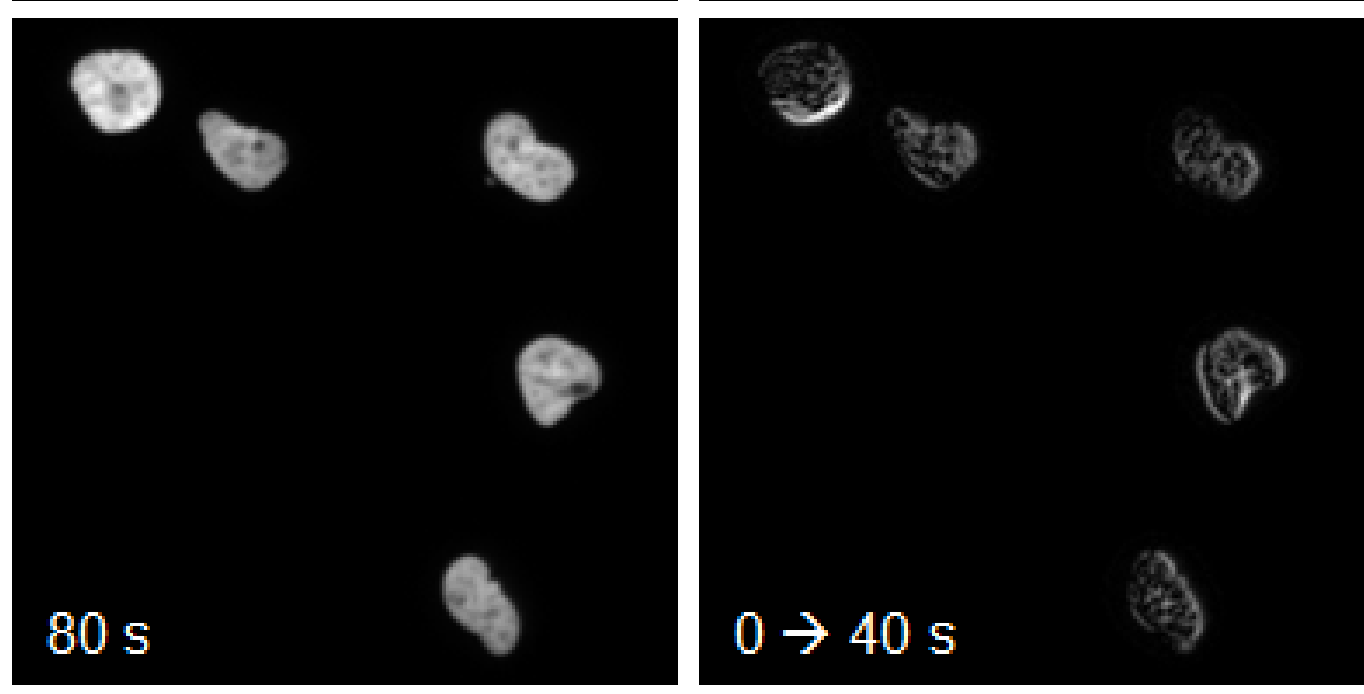

$40 \mathrm{~s}$

$0 \rightarrow 40 \mathrm{~s}$

\section{6



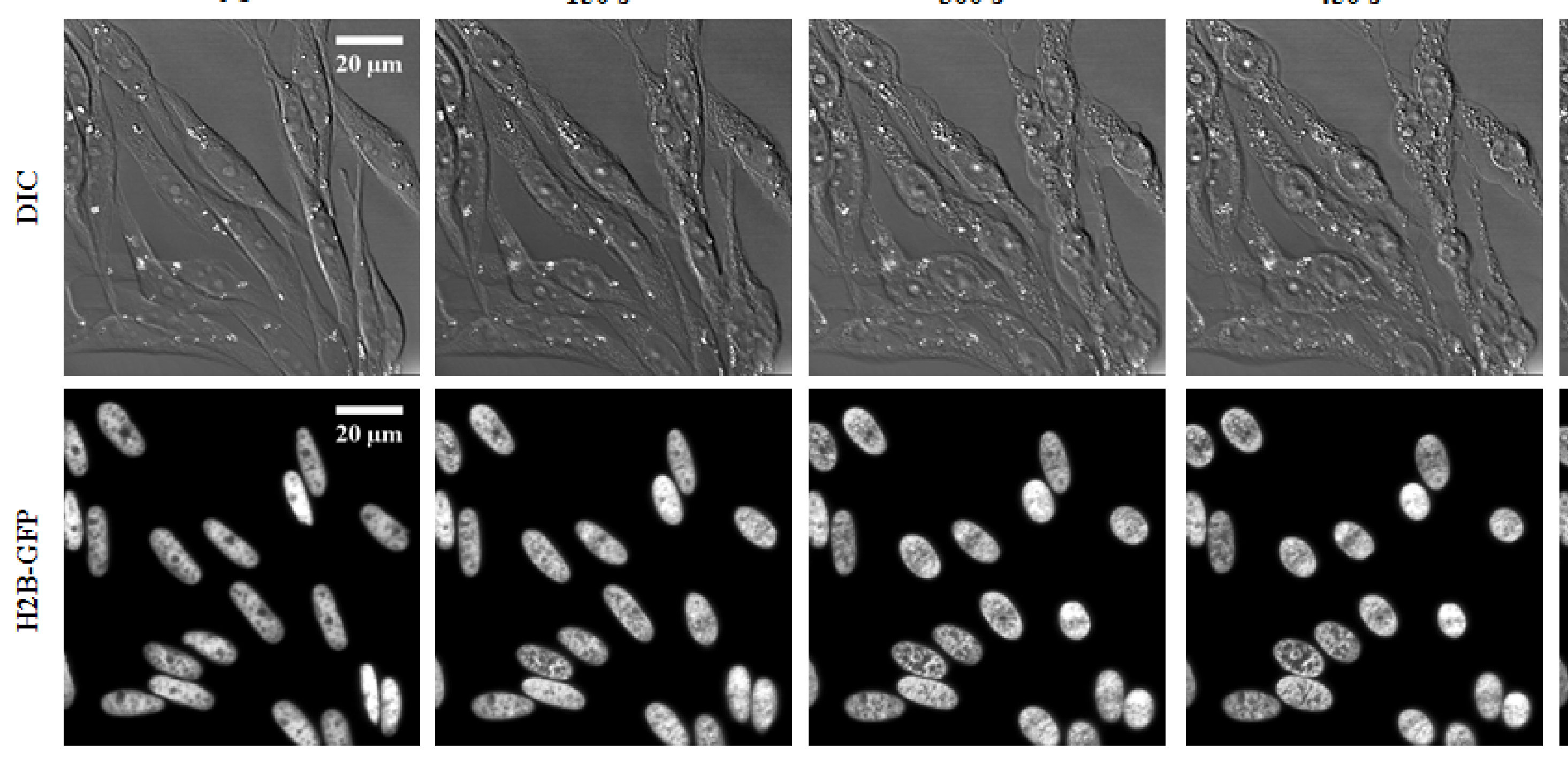

$\begin{array}{lll}0 & 0 \\ 0 & 0 & 0 \\ \pi^{2} & 0 & 0\end{array}$

$0_{0}^{0}$

$\int_{0}^{0} 0^{0}$

$\infty^{\circ} 0$

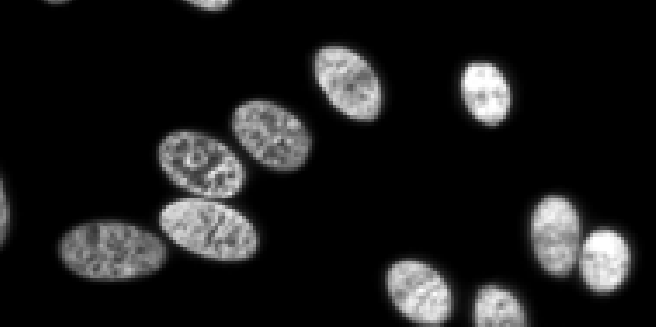

$0_{0}^{0} 0^{\circ}$

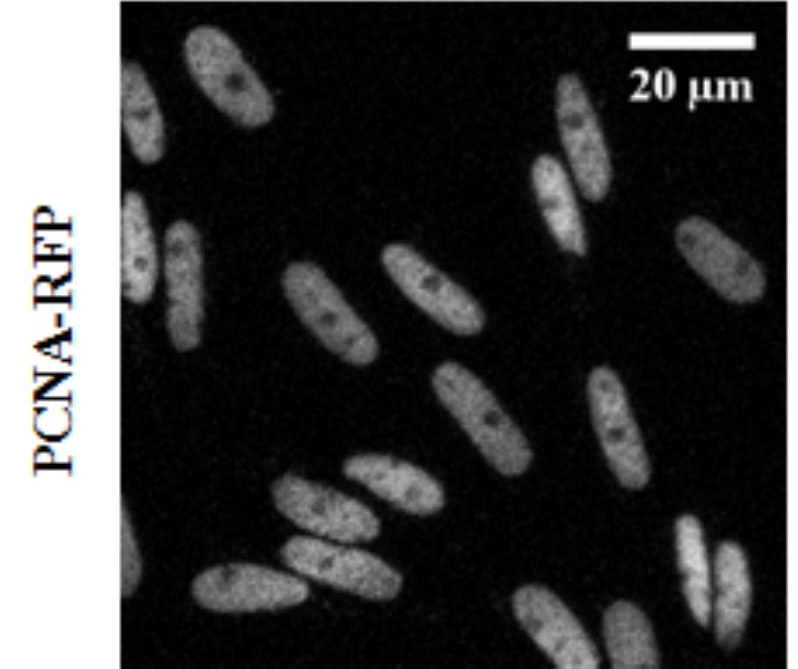

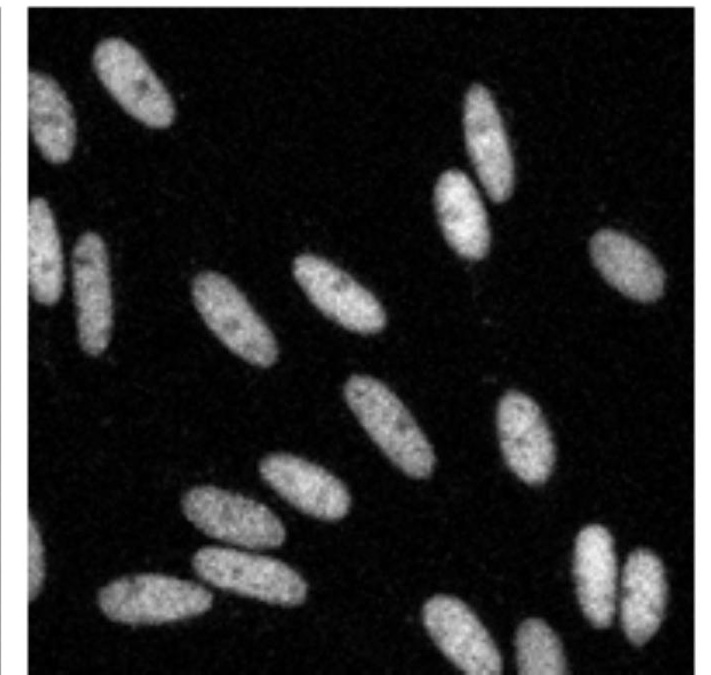

$\begin{array}{ll}t_{0} & 0 \\ -8^{\circ} & 0\end{array}$

$5 e^{8}$
$-6^{8}$

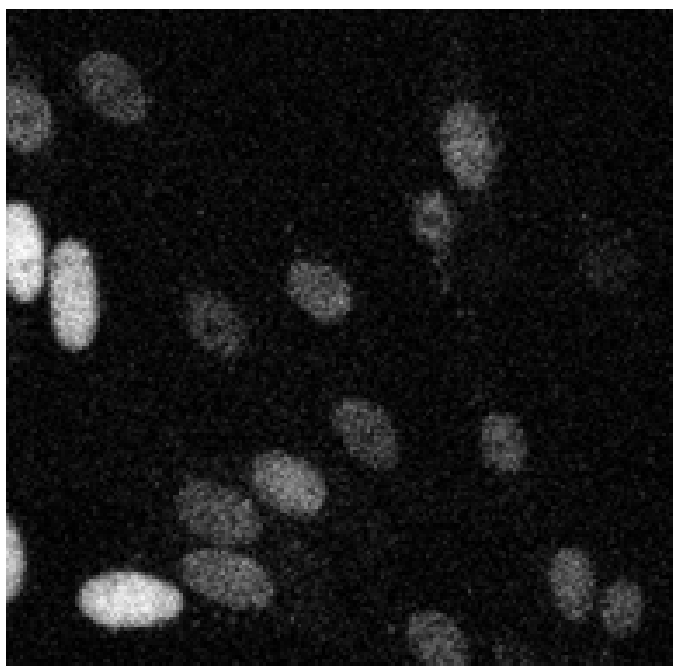

3

$8^{\circ}$

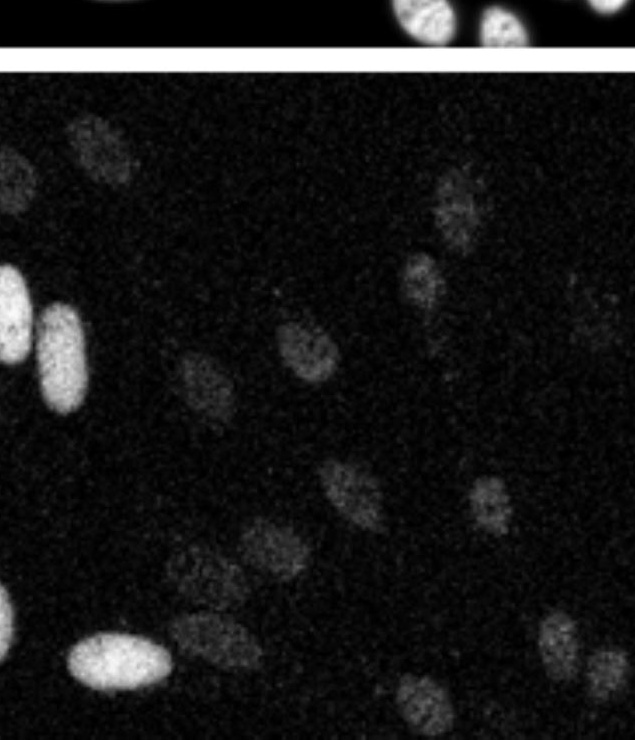



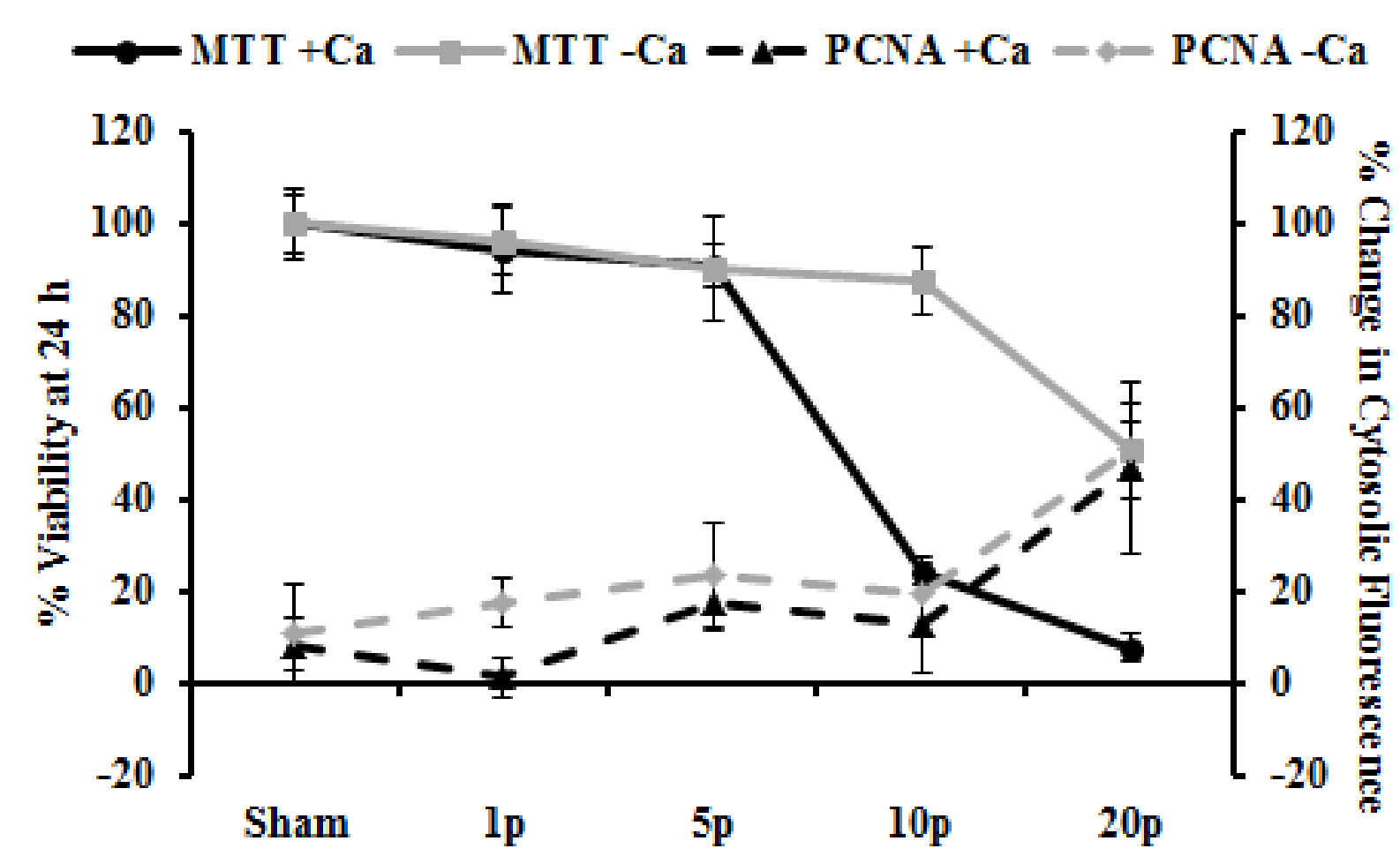

B

Sham

1 Pulse

5 Pulses

10 Pulses

20 Pulses
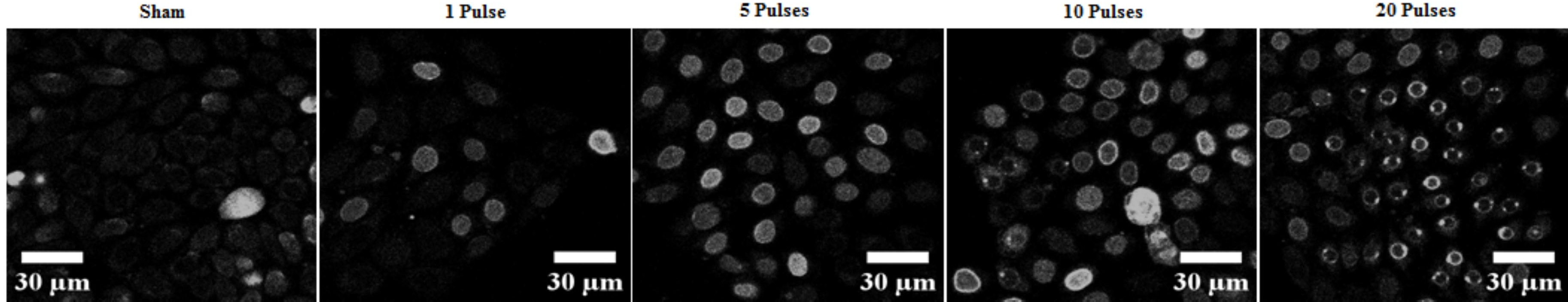
